\title{
Gene Silencing by siRNA Nanoparticles Synthesized via Sonochemical Method
}

\author{
Shimanovich $U^{1,2 *}$, Munder $A^{2}$, Loureiro $A^{3,4}$, Azoia NG ${ }^{3}$, Andreia C Gomes ${ }^{4}$, Cavaco-Paulo $A^{3}$, Gedanken $A^{2}$ and Gruzman $A^{2 \star}$ \\ 'Department of Chemistry, University of Cambridge, Lensfield road, Cambridge, CB2 1EW, UK \\ ${ }^{2}$ Department of Chemistry, Bar-Ilan University, Ramat-Gan 52900, Israel \\ ${ }^{3}$ CEB - Center of Biological Engineering, University of Minho, 4710-057 Braga, Portugal \\ ${ }^{4}$ CBMA (Center of Molecular and Environmental Biology), Department of Biology, University of Minho, 4710-057 Braga, Portugal
}

\begin{abstract}
The knowledge that small RNAs can affect gene expression has had a tremendous impact on basic and applied research, and gene silencing is currently one of the most promising new approaches for disease therapy. However, RNAs cannot easily penetrate cell membranes, therefore RNA delivery become one of the major challenges for gene silencing technology. In the current paper we discuss a general approach for converting siRNA molecules into a dense siRNA nanoparticles using environmentally friendly sonochemical method. The RNA nanoparticulation enhance its gene-silencing activity in vascular bovine endothelial as well as in cancer 293T/GFP-Puro cell lines without causing any toxic effect. We show that ultrasonic waves do not lead to RNA degradation or any changes in its chemical structure. Moreover, sonochemically produced siRNA nanoparticles have been shown to be resistant to a variety of environmental stresses including $\mathrm{pH}$ levels, enzymes and temperatures, hence solving problem of the short half-life of the RNA molecules. As the siRNA nanoparticles are biocompatibile and biodegradabile, and their RNA release properties may be controlled within limits, sonochemical formation of siRNA nanoparticles represent a new promising approach for generation of functional bionano materials.
\end{abstract}

Keywords: Nanoparticles; Bionano materials; siRNA nanoparticles; Gene silencing

\section{Introduction}

RNA, has recently emerged as an important nanotechnology platform due to its extraordinary diversity in structure and function $[1,2]$. Small interfering RNA (siRNA), showed significant potential in new molecular approaches to down-regulate specific gene expression in mammalian cells [3]. In fact, targeted gene suppression by antisense DNA and siRNA has shown promising preclinical results, and/or is currently in clinical trials for a variety of diseases, including many forms of cancer (e.g., melanoma, neuroblastoma, and pancreatic adenocarcinoma), genetic disorders, and macular generation [4-6]. Despite the high therapeutic potential of siRNA, its application for clinical medicine is still limited mainly due to the lack of appropriate delivery systems. In such a situation, the development of clinically suitable, safe, and effective drug-delivery biomaterials [7] are required for the widespread use of siRNA therapeutics for disease treatment. A variety of materials have been explored for delivering siRNAs including liposomal delivery [8,9], nanoparticles made of synthetic cationic polymers [10], polymeric protein spheres [11,12] and etc. However, conventional delivery materials such as lyposomes and polymeric systems are heterogeneous in size, composition and surface chemistry, and this can lead to suboptimal performance and potential toxicity. Therefore sonochemistry [13] offers an alternative synthetic pathway for conversion of RNA molecules, without chemical structure modification, into a dense RNA nanoparticles. The sonochemicallyinduced assembly of nanoparticles [14-16] from siRNA involves cooperative interaction of individual RNA molecules that assemble in a predefined manner to form a larger three-dimensional structure, which size and composition are precisely controlled. Moreover, the sonochemical siRNA nanoparticulation stabilize siRNA molecules. In this manner silencing activity of siRNA nanoparticles achieved through its dissociation to individual RNA molecules inside the cells. Nanoparticulate RNAs produced by this method have been shown to be resistant to a variety of environmental stresses including a wide range of $\mathrm{pH}$ levels, temperatures, and presence of RNases in the media. Being able to use nanoparticles with sizes of below $100 \mathrm{~nm}$ avoids the problem of the short half-life of small molecules in vitro [17] because of short retention time. Thus we probed the gene-silencing properties of nanoparticulate siRNA for endothelial bovine $[18,19]$ and 293T/ GFP-Puro [20] cell cultures. Endothelial bovine aorta cells are thought to play important roles in controlling hemostasis and blood vessel permeability [21]. Correspondingly, altered structure and function of endothelial cells might contribute significantly to the pathogenesis of disorders or the arterial wall. Additionally, this is a not easy task to lead to penetration of siRNA to normal, not cancer cells. Two silencing activities were successfully achieved for anti-GFP siRNA [22] and luciferase RNA molecules [23]. The sonochemical method for siRNA nanoparticle synthesis represents a new and promising approach for the generation of a new class of functional nanomaterials for therapeutic applications.

\section{Methods}

\section{Sonochemical synthesis of siRNA nanoparticles}

Nanoparticles were created via ultrasonic emulsification method from the aqueous siRNA solution of following concentrations: $2 \mu \mathrm{M}$,

*Corresponding author: U. Shimanovich, Department of Chemistry, University of Cambridge, Lensfield road, Cambridge, CB2 1EW, UK, Tel: 44-1223-336300, extn 63845; E-mail: us249@cam.ac.uk

Arie Gruzman, Department of Chemistry, Bar-Ilan University, Ramat-Gan, 52900 Israel. E.-mail:gruzmaa@biu.ac.il

Received April 01, 2014; Accepted June 05, 2014; Published June 10, 2014

Citation: Shimanovich U, Munder A, Loureiro A, Azoia NG, Gomes A, et al. (2014) Gene Silencing by siRNA Nanoparticles Synthesized via Sonochemical Method. J Nanomed Nanotechnol 5: 204. doi:10.4172/2157-7439.1000204

Copyright: (C) 2014 Shimanovich U, et al. This is an open-access article distributed under the terms of the Creative Commons Attribution License, which permits unrestricted use, distribution, and reproduction in any medium, provided the original author and source are credited. 
$3 \mu \mathrm{M}, 5 \mu \mathrm{M}, 10 \mu \mathrm{M}$ and $15 \mu \mathrm{M}$. Three types of siRNA molecules were converted into nanoparticles: 1) Cy3RNA of the following sequence 3'-/5Cy3/rArGrCrArCrArArUrGrCrGrUrCrUrGrUrUrGrGrC/ iCy3/rCrCrArGrCrUrGrCrUrArCrUrGrGrGrArGrCrUrU, Syntezza Bioscience, IDT, Israel). RNA containing Cy3-fluorescent tag (excitation $550 \mathrm{~nm}$, emission $570 \mathrm{~nm}$, quantum yield 0.04) was used for particles tracking inside the cells; 2) siRNA (target sequence: 5'-GCCATTCTATCCTCTAGAGGATGAAG-3') for renilla-firefly lucefirase silencing (Thermo scientific) was used for firefly gene silencing activity studies; and 3) anti-Green Fluorescent Protein (GFP) (Target sequence:5'-GATCCCCGCAAGCTGACCCTGAAG TTCTTCAAGAGAGAACTTCAGGGTCAGCTTGCTTTTTGGA AA-3'), Accell eGFP Control siRNA (Thermo Scientific) for silencing GFP gene. The siRNA, maintained in storage buffer (5X storage buffer composition: $300 \mathrm{mM} \mathrm{KCL}, 30 \mathrm{mM}$ HEPES pH 7.5 (with trace elemental impurities of $\mathrm{Na} \approx 0.05 \%, \mathrm{Cl} \approx 0.05 \%, \mathrm{Ca} \approx 0.01 \%$ and etc., see Thermo Scientific siRNA storage HEPES buffer trace elemental impurities), $1 \mathrm{mM} \mathrm{MgCl}_{2}$ ) was redissolved in doubly distilled water (DDW). The bottom of a high-intensity ultrasonic horn (Sonic and Materials, VC-600, $20 \mathrm{kHz}, 0.5$ in a Ti horn, at 30\% amplitude) was positioned at $1 \mathrm{~cm}$ from the water/air interface of the siRNA solution, followed by a sonication at an amplitude of $30 \%$ at $10^{\circ} \mathrm{C}( \pm 1)$ for 1,3 , 5,10 and 15 minutes (employing an acoustic power of $\approx 58 \mathrm{~W} / \mathrm{cm}^{2}$ ). After nanoparticle preparation was accomplished, unreacted free siRNA was removed using two separation methods: 1) precipitation of nanoparticles by centrifugation at $13000 \mathrm{rpm}$ for $15 \mathrm{~min}$ or 2) by dialysis in PBS. siRNA was quantified by measuring its UV absorbance at $260 \mathrm{~nm}$, using NanoDrop $2000 \mathrm{UV}$-Spectrophotometer. The free siRNA (not incorporated into the nanoparticles) was removed from the solution by dialyzing (using a dialysis tubing cellulose membrane with molecular weight cut-off of $14000 \mathrm{Da}$, Sigma-Aldrich) ain PBS for $24 \mathrm{~h}$. The dialysis was conducted for $7 \mathrm{~mL}$ of sample in $250 \mathrm{~mL}$ of PBS, which was renovated twice. siRNA was then quantified spectroscopically, before and after dialysis, using a NanoDrop 2000 Spectrophotometer. The obtained results showed only $<5 \%$ of siRNA that was estimated to be free and thus removed by dialysis.

\section{Efficiency studies for siRNA nanoparticles formation}

The efficiency of the ultrasonic method in converting siRNA molecules into nanoparticles was calculated using UV-Vis spectroscopy (Carry100 spectrophotometer) for the absorbance values measured at $260 \mathrm{~nm}$. The absorption of the individual unreacted siRNA molecules (for both separation methods: centrifugation and dialysis) was measured by collecting the upper part of the aqueous solution after the separation of the nanoparticles by centrifugation at $13000 \mathrm{rpm}$ for $15 \mathrm{~min}$ or by measuring free RNA in dialysis media (washing solution outside the dialysis bag). Subtracting the amount of the free RNA from the original amount of the RNA molecules we obtained the total amount of siRNA converted into nanoparticles. The calculated efficiency of siRNA nanoparticles formation separated by centrifugation and dialysis methods was found to be $91 \%$ and $95 \%$, respectively. We assume that these small differences in the efficiency values come from the partial dissociation of siRNA nanoparticles during the centrifugationseparation process.

\section{siRNA nanoparticles stability studies}

The stability of the siRNA nanoparticles was studied by HRSEM microscopy. For the enzymatic stability studies of siRNA nanoparticles the RNase type-IIA (Ribonuclease A from bovine pancreas Type II-A, Sigma) was added to the particles dispersion following standard protocol (Sigma). Then the nanoparticles aqueous solution was analyzed using dynamic light scattering (following the disappearance of nanoparticles peak) and high resolution electron microscopy analysis. The siRNA nanoparticles were found to be stable in the presence of RNase II for 3 hours. In order to measure the stability of siRNA nanoparticles at different temperatures $\left(4^{\circ} \mathrm{C}, 25^{\circ} \mathrm{C}\right.$ and $\left.37^{\circ} \mathrm{C}\right)$, the temperature of nanoparticles solution was adjusted either by placing the reaction flask in refrigerator $\left(4^{\circ} \mathrm{C}\right)$ or heating the solution up to $37^{\circ} \mathrm{C}$. The nanoparticles dissociation was followed by above described methods. siRNA nanoparticles were found to be stable for 1 month at $4^{\circ} \mathrm{C}$, for 24 hours at $25^{\circ} \mathrm{C}$ and for $70 \mathrm{~min}$ at $37^{\circ} \mathrm{C}$. The stability of nanoparticles in media with different $\mathrm{pH}$ values was checked adjusting $\mathrm{pH}$ by adding to nanoparticles solution concentrated $\mathrm{HCl}$ or $\mathrm{NaOH}$. The nanoparticles dissociation was followed by above described methods. The siRNA nanoparticles were found to be stable for 24 hours at $\mathrm{pH}$ values ranging from 4.5 to 9 .

The dissociation of siRNA nanoparticles as well as free siRNA molecules degradation under ultrasonic waves was followed by primer extension method. The products were separated on 6\% polyacrylamide/7 M urea gels and visualized by autoradiography (See results in Supporting Information).

\section{Introduction of siRNA nanoparticles into the cells and gene silencing activity assay}

Vascular endothelial cells were prepared from segments of the descending bovine aorta obtained from a local slaughterhouse (Kibbutz Lahav, Israel). Bovine aortic endothelial cells were harvested by a modification of the method described elsewhere [24], washed with phosphate buffer solution (PBS), and scraped gently with a sterile stainless steel spatula. The scraped cells were plated on fibronectincoated tissue culture dishes in DMEM containing 10\% FCS, $50 \mathrm{mg} /$ $\mathrm{ml}$ penicillin and $50 \mathrm{mg} / \mathrm{ml}$ streptomycin. Areas of pure endothelial cells were enclosed with cylinder rings, trypsinized, and replated on fibronectin-coated dishes. The cultures derived from several aortae were passages weekly (1:3 split ratio) and confluent, highly organized cultures between the $4^{\text {th }}$ and the $18^{\text {th }}$ passages were used for experiments. The cultures were maintained at $37^{\circ} \mathrm{C}$ in a humidified $5 \% \mathrm{CO}_{2}$ incubator The Cy3RNA nanoparticles suspension $(3.8 \mathrm{uM})$ was added to the cells media and incubated for $1 \mathrm{~h}$. The internalization of the nanoparticles inside the cells was visualized using confocal microscopy.

For gene silencing activity tests, the bovine cells were incubated in 96 well plate $\left(4 \times 10^{3}\right.$ cells/well $)$ with lucefirase RNA nanoparticles created via 1 and 3 min sonication time $(3.8 \mathrm{uM})$ and free siRNA, for 1 $\mathrm{h}$, then the media was replaced followed by additional incubation for 48 hours. The gene silencing activity was monitored using Pierce RenillaFirefly Lucefirase dual assay kit protocol (Thermo scientific). The firefly gene repression was measured at $613 \mathrm{~nm}$ fluorescent emission wavelength. The GFP gene silencing activity was probed for 293T/GFPPuro cell line from Cell Biolabs that was routinely grown in T75 tissue culture flasks at $37^{\circ} \mathrm{C}$, in a humidified $5 \% \mathrm{CO}_{2}$ atmosphere. The cells were grown in Dulbecco's Modified Eagle's Medium containing $4.5 \mathrm{~g} / \mathrm{L}$ glucose and $1.5 \mathrm{~g} / \mathrm{L}$ sodium bicarbonate (Sigma), supplemented with $2 \mathrm{mM}$ L-glutamine, $10 \%$ of fetal bovine serum (FBS), $0.1 \mathrm{mM}$ MEM Non-Essential Amino Acids (NEAA), 1\% Streptomycin-Penicillin and $2 \mu \mathrm{g} / \mathrm{mL}$ Puromycin. 293T/GFP cells were seeded in 24 well plates (TPP, Switzerland) at a density of $7.5 \times 10^{4}$ cells/well and incubated overnight to promote cell adhesion. Cells were exposed to solutions of antiGFP siRNA and to anti-GFP siRNA nanoparticles at a concentration of $1 \mu \mathrm{M}$ and the gene silencing effect was monitored directly under a fluorescence microscopy (Olympus IX71). The quantification of percentage of GFP silencing was monitored by measuring fluorescence 
Citation: Shimanovich U, Munder A, Loureiro A, Azoia NG, Gomes A, et al. (2014) Gene Silencing by siRNA Nanoparticles Synthesized via Sonochemical Method. J Nanomed Nanotechnol 5: 204. doi:10.4172/2157-7439.1000204

intensities emitted from untreated and treated cells (emission $520 \mathrm{~nm}$ ). These values were determined by treatment of images correspondent to different conditions.

\section{Cell viability assay}

Endothelial bovine aorta cells were incubated in a 96 well plate with $1 \mathrm{uM}, 4 \mathrm{uM}$ and $10 \mathrm{uM}$ of siRNA nanoparticles for $1 \mathrm{~h}$, washed and followed by additional incubation for $24 \mathrm{~h}$ at $37^{\circ} \mathrm{C}$. After incubation was accomplished, the cell viability was measured using CellTiter 96 Aqueous One Solution Cell Proliferation Assay (MTS, Promega) according to standard protocol.

\section{Characterization methods}

The morphology of the siRNA nanoparticles was examined by high resolution electron microscope (HRSEM, FEI, Magellan $400 \mathrm{~L}$ ) and scanning transmission electron microscopy (STEM). For the HRSEM analysis the samples were prepared by depositing the aqueous dispersions, without further purification, on a glass-slide, drying and coating with a thin layer of carbon. For STSEM analysis the samples were deposited on copper grids with carbon film 400 meshes, $3 \mathrm{~mm}$ diameter, and analyzed in a NOVA Nano SEM 200 FEI. The microscope
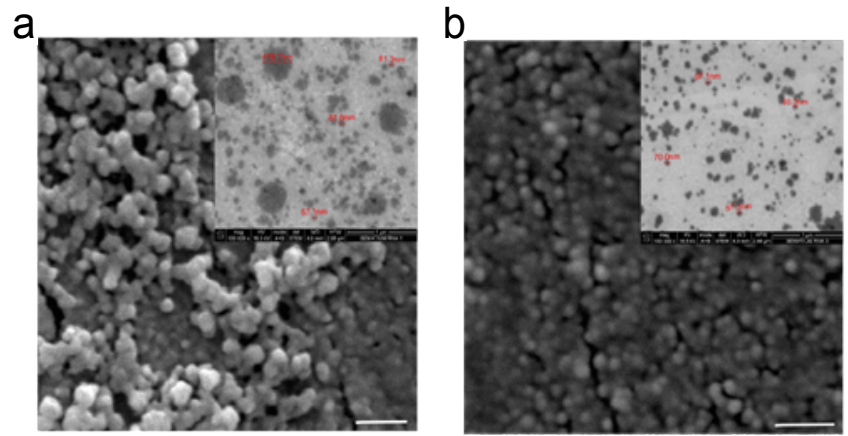

C

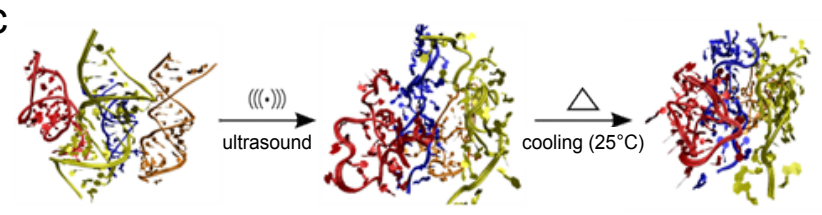

d

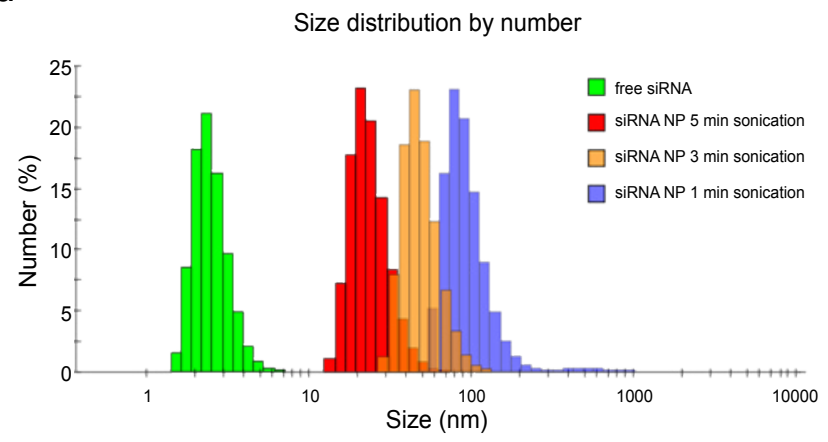

Figure 1: (a) HRSEM images of siRNA nanoparticles formed within 1 min of sonication time and (b) within 3 min sonication time. The corresponding STEM images of siRNA nanoparticles are shown in the right corner of each image Scale bars $=100 \mathrm{~nm}$; (c) diagram for the mechanism of sonochemical siRNA nanoparticles formation resolved from MD simulations of siRNA SiRNA nanoparticles formation resolved from MD simulations of SiRNA
molecules in water; (d) size distribution (obtained from DLS analysis) histogram for free siRNA molecules, siRNA nanoparticles created within 1, 3 and 5 min sonication time. The exact are shown in Supportin Information. was operated at $10 \mathrm{kV}$ and samples viewed at a working distance of 8 $\mathrm{mm}$ and $10000 \mathrm{x}$ magnification.

For fluorescent and confocal microscopy analysis the samples (bovine cells loaded with Cy3 RNA nanoparticles and 293T/GFP-Puro cell incubated with ant-GFP-siRNA nanoparticles) were analyzed by confocal microscopy (Laser Scan Confocal, Zeiss Microscope) using tunable Argon $514 \mathrm{~nm}$ laser at $30 \mathrm{~mW}$ (for yellow excitations), and fluorescent (Olympus IX71) microscope using GFP filter $(488 / 520 \mathrm{~nm})$.

DLS measurements and zeta-potential measurements were carried out on an ALV/CGS-3 compact goniometer system equipped with an ALV/LSE-5003 light scattering electronic and multiple digital correlator, and a $632.8 \mathrm{~nm}$ JDSU laser 1145P. DLS and zeta-potential experiments were carried out on a siRNA nanoparticles solution. Each measurement took $10 \mathrm{~s}$; the electrical charge distribution was obtained by averaging ten DLS measurements.

The Inductively Coupled Plasma analysis was performed for diluted (with DDW) siRNA nanoparticles solution (initial concentration 3.8 $\mathrm{uM})$ to $50 \mathrm{ml}$ of total volume on atomic emission spectrometer. The following ions were detected in the RNA solution: $\mathrm{Na}^{+}, \mathrm{Mg}^{2+}$ and $\mathrm{Ca}^{2+}$.

The quality of the sonochemically treated siRNA was assessed by a primer extension technique and compared to the untreated siRNA. The siRNA molecules converted into the nanoparticles were extracted using a phenol:chloroform extraction method and further precipitated with ethanol according to the manufacturer's instructions. The products were visualized on polyacrylamide gel (See results in Supporting Information).

\section{Results and Discussion}

To explore the potential nano confinement to silence the genes, we formed siRNA nanoparticles by passing ultrasonic waves through the aqueous siRNA solution. The fraction of RNA converted to particles was measured by monitoring the concentration of free RNA by UV absorption, revealing that the conversion efficiency of over $90 \%$ (See Methods). We further investigated the dependence of the morphology and size of the siRNA nanoparticles formed upon different exposure times to ultrasonic waves by high resolution scanning electron microscopy (HRSEM) and scanning transmission electron microscopy (STEM) (Figure 1a). A reduction in size was observed for nanoparticles formed under longer exposure time of 3 min with particle size of $65 \mathrm{~nm}$ (Figure $1 \mathrm{~b}$ ), while for shorter sonication time $(1 \mathrm{~min})$ the average size of siRNA nanoparticles was about $80 \mathrm{~nm}$ (Figure 1a). Interestingly, the generation of particles under the longer exposure time, for more than $5 \mathrm{~min}$, led to smaller particle size of about $15 \mathrm{~nm}$ with reduction in efficiency of nanoparticle formation for $50 \%$. The exposure of siRNA molecules to ultrasound for longer than 15 min led to complete RNA degradation. We propose that this effect is due to the fact that cavitation bubbles produced in aqueous media collapse in an implosive manner and generate locally extreme physico-chemical conditions that promote nanoparticles formation or, in its excess, lead to particles dissociation and RNA degradation. To this effect, we probed the stability of RNA nanoparticles under ultrasonic waves by exposing nanoparticles to ultrasound and monitored the particles dissociation. After $10 \mathrm{~min}$ exposure, there were no particles detected in the solution with complete degradation of free RNA molecules was achieved after 15 min exposure time (See Supporting Information). It is worth to mention that exposure of RNA molecules to ultrasonic frequencies higher than $40 \%$ amplitude (See methods section) lead to complete RNA degradation. 

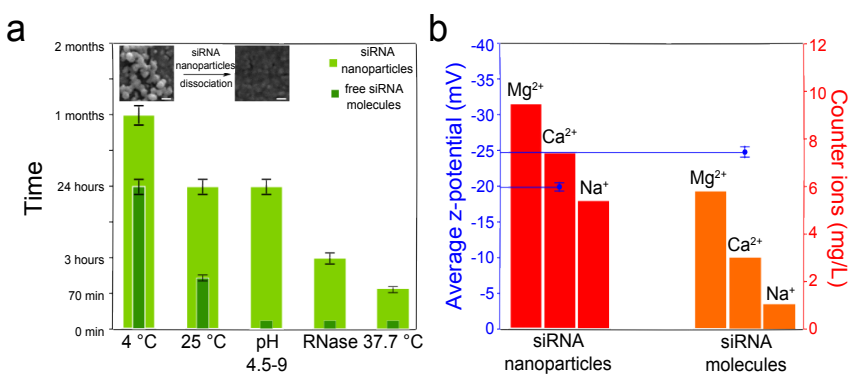

Figure 2: (a) Stability studies for siRNA nanoparticles and free siRNA molecules as a function of temperature $\left(4^{\circ} \mathrm{C}, 25^{\circ} \mathrm{C}\right.$ and $\left.37^{\circ} \mathrm{C}\right), \mathrm{pH}$ changes (from 4,5 to 9 ) and presence of RNases in solution. HRSEM images of siRNA nanoparticles before and after dissociation are shown at the top part of the graph. Scale bars $=100 \mathrm{~nm}$; (b) chart summarizing average zeta-potential (in $\mathrm{mV}$ ) and counter ions concentrations $(\mathrm{mg} / \mathrm{L})$ for nanoparticulate siRNA and free siRNA molecules.

In order to obtain the more detailed understanding of the mechanism of siRNA nanoparticles formation we followed the RNA molecular changes by means of molecular dynamic simulations (MD). The MD results are presented in Figure 1c. The simulations show that the subsequent application of ultrasonic energy leads to reorganization of RNA structure and further formation of dense siRNA nanoparticle.

The stability of the sonochemically formed siRNA nanoparticles was probed in the presence of degrading RNase enzyme, for wide range of $\mathrm{pH}$ and temperatures varying from $4^{\circ} \mathrm{C}$ to $37^{\circ} \mathrm{C}$ (See Methods). The effect of $\mathrm{pH}$, temperature and enzymatic changes in the siRNA nanoparticles stability in solution was studied by HRSEM microscopy following the nanoparticles dissociation. The nanoparticulate content was measured in the lower aqueous phase after nanoparticles separation (See methods). Under bulk conditions, siRNA nanoparticles remained stable for approximately 24 hours followed by nanoparticles dissociation process. By contrast, we found that at $4^{\circ} \mathrm{C}$ the dense nanoparticles retained its stability for 1 month and for $70 \mathrm{~min}$ at $37^{\circ} \mathrm{C}$, suggesting that the dense siRNA packing in the nanoparticles structure protects the molecules effectively against degradation under ambient conditions. It is worth to mention that free siRNA molecules are stable under ambient conditions for 1.5-2 hours and up to 24 hours at $4^{\circ} \mathrm{C}$ and unstable at $37^{\circ} \mathrm{C}$. siRNA nanoparticles were found to be stable at $\mathrm{pH}$ values varying from 4.5 to 9 for $24 \mathrm{~h}$ (average value $\pm 4 \mathrm{~h}$ ). The further decrease or increases in $\mathrm{pH}$ of the dispersion lead to particles dissociation followed by RNA degradation. The sonochemically formed siRNA nanoparticles were found to be stable in the presence of degradative RNase enzymes for at least 3 hours. The results of siRNA stability studies are presented in Figure 2a. siRNA nanoparticles were found to be negatively charged with an electrical charge of $-19.9 \mathrm{mV}$. The electrical charge of native RNA molecules was found to be $-31.8 \mathrm{mV}$ (Figure 2b). Due to the fact that sonochemically formed nanoparticles are negatively charged, they have a tendency to repel each other. As a result they stay dispersed and colloidal in water. The zeta potential measurements were performed on a dynamic light scattering apparatus. The negative charge indicates that the negative phosphate groups are directed from the nanoparticles interface towards the solution. In order to understand the origin of difference in electrical charge between the native siRNA molecules and siRNA nanoparticles, we quantified the counter ions fraction by inductively coupled plasma (ICP). Due to the fact that all the experiments were performed in DDW, the only source of the detected counter ions is RNA storage buffer (See Methods section). Interestingly, the fraction of counter ions of $\mathrm{Na}^{+}$,
$\mathrm{Mg}^{2+}$ and $\mathrm{Ca}^{2+}$ in siRNA nanoparticles was found to be higher than for native RNA molecules (Figure $2 \mathrm{~b}$ ). This formulation and composition of RNA nanoparticle structure allows neutralization of the negatively charged phosphate groups localized at the outer surface of the siRNA nanoparticles.

The transfer of siRNA into non-viral cells is a complicated procedure because it involves the use of different mediators. In the current study the nanoparticles were successfully introduced into the aorta bovine endothelial cells without use of any additional transfection agents. The maximal particle size that are able to penetrate the cells, can reach $400-500 \mathrm{~nm}$, while the relative size of the cells is about $20 \mu \mathrm{m}$. Thus the nanoscale size of siRNA particles have an advantage over the conventional micronscale delivery systems. Fluorescently labeled Cy3siRNA nanoparticles spontaneously penetrated into the cells. Figure 3a depicts the entrance of the siRNA nanoparticles into the bovine endothelial cell. A control experiment shows that no fluorescent signal was detected when the Cy3-siRNA molecules were exposed to cells (See methods) due to the low efficiency of the internalization of RNA in the monomeric form and as a consequence of the dilution of any Cy3-siRNA inside the cell to the entire cytoplasmic volume. Next, we explored the silencing activity of siRNA nanoparticles. The ability of lucefirase siRNA and anti-GFP siRNA nanoparticles to silence the genes was probed on endothelial bovine and 293T/GFP-Puro cell cultures (Figure $3 b$ and $c$ ). The observation confirms the better silencing by siRNA nanoparticles compared to siRNA molecules in its native state (as a negative control), since the repression of desired genes (firefly for

a
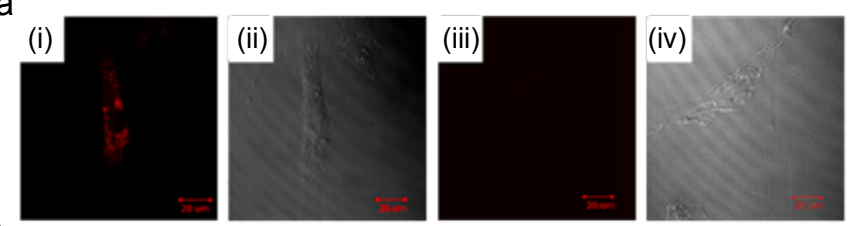

$\mathrm{b}$
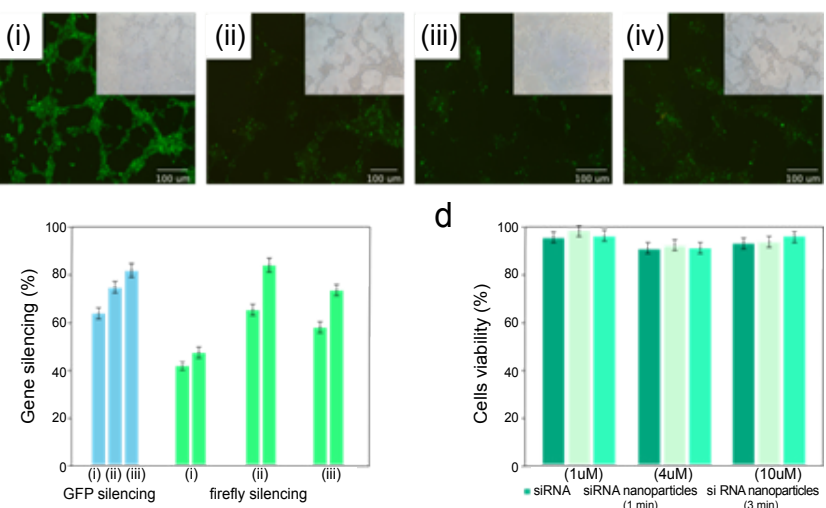

d

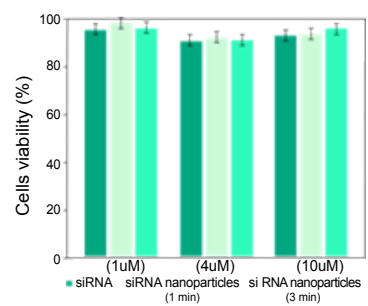

Figure 3: (a) Introduction of Cy3RNA nanoparticles into the aorta bovine endothelial cells: (i) fluorescent image of endothelial cell loaded with Cy3RNA nanoparticles, (ii) DIC image of i; (iii) fluorescent image of endothelial cell incubated with free siRNA; (iv) DIC image of iii. (b) fluorescent images of the GFP gene silencing in 293T/GFP-Puro cells using anti-GFPsiRNA nanoparticles: (i) untreated cells, (ii) cells treated with nanoparticles prepared nanoparticles: (i) untreated cells, (ii) cells treated with nanoparticles prepared
via 1 min sonication time, (iii) cells treated with nanoparticles prepared via 3 min sonication time, (iv) cells incubated with free anti-GFPsiRNA. (c) silencing results of GFP and firefly genes (left green bars indicate renila silencing efficiency). The gene silencing activity was probed on the cells treated with: (i) free siRNA molecules, (ii) siRNA nanoparticles created via 1 min sonication and (iii) siRNA nanoparticles created via 3 min sonication. (d) min sonication and (iii) siRNA nanoparticles created via 3 min sonication. (d)
cell viability test for free siRNA molecules, siRNA nanoparticles created via 1 min sonication and siRNA nanoparticles created via 3 min sonication for bovine aorta endothelial cell lines. 
Citation: Shimanovich U, Munder A, Loureiro A, Azoia NG, Gomes A, et al. (2014) Gene Silencing by siRNA Nanoparticles Synthesized via Sonochemical Method. J Nanomed Nanotechnol 5: 204. doi:10.4172/2157-7439.1000204

Page 5 of 5

endothelial cells and GFP for 293T/GFP-Puro cells) was achieved by treating cell lines with siRNA nanoparticles. Figure $3 \mathrm{~b}$ and $\mathrm{c}$ depicts the gene silencing results for firefly gene silencing in endothelial cells and GFP gene silencing in 293T/GFP-Puro. Maximal silencing effect (for GFP and Luciferase silencing via nanoparticles created within 3 min sonication time $\approx 80 \% \pm 3.4$ silencing), comparable with Lipofectamine and polyethyleneimine ( $\geq 80 \%$ av. silencing efficiency reported by Maurisse et al.) was achieved. However, for nanoparticles created within 1 min sonication time, the lower silencing effect of about $60 \%$ was achieved.

Finally we tested whether or not the observed silencing effect is resulted from siRNA nanoparticles toxicity. In order to examine the biocompatibility of the siRNA nanoparticles for gene silencing applications, their toxicity was examined using MTS toxicity assay (See Methods). The nanoparticlulate siRNA was found to be non-toxic for the cells as shown in Figure 3d.

\section{Conclusions}

In conclusion, we described a general approach for conversion of siRNA molecules into the dense siRNA nanoparticles using environmentally friendly ultrasonic method. Our system does not contain protein or peptides, and thus the use of such protein-free nanoparticles to avoid immune response would allow for longterm administration in the treatment of chronic diseases. SiRNA nanoparticulate structures produced by ultrasonic method, in addition to gene silencing abilities, have been shown to be resistant to a variety of environmental stresses including a wide range of $\mathrm{pH}$ and temperature levels and presence of enzymes. Understanding and controlling the siRNA behavior opens the variety of possible applications in the field of nanomedicine and bionanotechnology.

\section{References}

1. Guo $P(2010)$ The emerging field of RNA nanotechnology. Nat Nanotechnol 5 : 833-842.

2. Khaled A, Guo S, Li F, Guo P (2005) Controllable self-assembly of nanoparticles for specific delivery of multiple therapeutic molecules to cancer cells using RNA nanotechnology. Nano Lett 5: 1797-1808.

3. Xia H, Mao Q, Paulson HL, Davidson BL (2002) siRNA-mediated gene silencing in vitro and in vivo. Nat Biotechnol 20: 1006-1010.

4. Whitehead KA, Langer R, Anderson DG (2009) Knocking down barriers: advances in siRNA delivery. Nat Rev Drug Discov 8: 129-138.

5. Blagbrough IS, Zara C (2009) Animal models for target diseases in gene therapy--using DNA and siRNA delivery strategies. Pharm Res 26: 1-18.

6. Herweijer $\mathrm{H}$, Wolff JA (2003) Progress and prospects: naked DNA gene transfer and therapy. Gene Ther 10: 453-458.

7. Godbey WT, Wu KK, Mikos AG (2001) Poly(ethylenimine)-mediated gene delivery affects endothelial cell function and viability. Biomaterials 22: 471-480.

8. Templeton NS, Lasic DD, Frederik PM, Strey HH, Roberts DD, et al. (1997) Improved DNA: liposome complexes for increased systemic delivery and gene expression. Nat Biotechnol 15: 647-652.
9. Alton EW, Middleton PG, Caplen NJ, Smith SN, Steel DM, et al. (1993) Noninvasive liposome-mediated gene delivery can correct the ion transport defect in cystic fibrosis mutant mice. Nat Genet 5: 135-142.

10. Lu W, Sun Q, Wan J, She Z, Jiang XG (2006) Cationic albumin-conjugated pegylated nanoparticles allow gene delivery into brain tumors via intravenous administration. Cancer Res 66: 11878-11887.

11. Putnam D (2006) Polymers for gene delivery across length scales. Nat Mate 5: 439-451.

12. Shimanovich U, Tkacz ID, Eliaz D, Cavaco-Paulo A, Michaeli S, et al. (2011) Encapsulation of RNA molecules in BSA microspheres and internalization into Trypanosoma brucei parasites and human U2OS cancer cells. Advanced Functional Materials 21: 3659-3666.

13. Suslick KS (1998) Sonochemistry. Kirk-Othmer Encyclopedia of Chemical Technology (1998).

14. Gedanken A (2004) Using sonochemistry for the fabrication of nanomaterials. Ultrason Sonochem 11: 47-55.

15. Mason TJ, Lorimer JP (2002) Applied sonochemistry. Weinheim: Wiley-vch.

16. Einhorn C, Einhorn J, Luche JL (1989) Sonochemistry-The Use of Ultrasonic Waves in Synthetic Organic Chemistry. Synthesis 1989: 787-813.

17. Bartlett DW, Su H, Hildebrandt IJ, Weber WA, Davis ME (2007) Impact of tumorspecific targeting on the biodistribution and efficacy of siRNA nanoparticles measured by multimodality in vivo imaging. Proc Natl Acad Sci U S A 104 $15549-15554$

18. Pollock JS, Förstermann U, Mitchell JA, Warner TD, Schmidt HH, et al. (1991) Purification and characterization of particulate endothelium-derived relaxing factor synthase from cultured and native bovine aortic endothelial cells. Proc Natl Acad Sci 88: 10480-10484.

19. Gospodarowicz D, Moran J, Braun D, Birdwell C (1976) Clonal growth of bovine vascular endothelial cells: fibroblast growth factor as a survival agent. Proc Nat Acad Sci U S A 73: 4120-4124.

20. Agami R, Blandino G, Oren M, Shaul Y (1999) Interaction of c-Abl and p73alpha and their collaboration to induce apoptosis. Nature 399: 809-813.

21. Hirase T, Staddon JM, Saitou M, Ando-Akatsuka Y, Itoh M, et al. (1997) Occludin as a possible determinant of tight junction permeability in endothelia cells. J Cell Sci 110: 1603-1613.

22. Sui G, Soohoo C, Affar el B, Gay F, Shi Y, et al. (2002) A DNA vector-based RNAi technology to suppress gene expression in mammalian cells. Proc Nat Acad Sci U S A 99: 5515-5520.

23. Johnson BW, Olson KE, Allen-Miura T, Rayms-Keller A, Carlson JO, et al. (1999) Inhibition of luciferase expression in transgenic Aedes aegypti mosquitoes by Sindbis virus expression of antisense luciferase RNA. Proc Natl Acad Sci U S A 96: 13399-13403.

24. Sasson S, Gorowits N, Joost HG, King GL, Cerasi E, et al. (1996) Regulation by metformin of the hexose transport system in vascular endothelial and smooth muscle cells. Br J Pharmacol 117: 1318-1324.

\footnotetext{
This article was originally published in a special issue, Nanotechnology: Targeted Drug Delivery handled by Editor(s). Dr. Sami M. Nazzal, University of Louisiana at Monroe, USA; Dr. Kytai Troung Nguyen, University of Texas at Arlington, USA
} 